\title{
ENSINO EM TEMPOS DE TDIC: PERCEPÇÕES E PRÁTICAS DE PROFESSORES DO ENSINO SUPERIOR
}

\author{
TEACHING IN ICT TIMES: PERCEPTIONS AND PRACTICES OF HIGHER \\ EDUCATION TEACHERS
}

DOI: http://dx.doi.org/10.23926/RPD.2526-2149.2019.v4.n2.p823-833.id512

\section{Rogério José Schuck \\ Doutor em Filosofia \\ (PUCRS) \\ Professor na Universidade do \\ Vale do Taquari (Univates) \\ rogerios@univates.br}

\section{Adriano Edo \\ Neuenfeldt}

Mestre em Educação

(UFSM)

Doutorando em Ensino na

Universidade do Vale do

Taquari (Univates)

adrianoneuenfeldt@universo

univates.br

\section{Lara Kalkmann \\ Goulart}

Graduanda em Psicologia na

Universidade do Vale do

Taquari (Univates)

laratuxa@gmail.com
Resumo: A presença das tecnologias digitais na sociedade contemporânea leva-nos a refletir sobre o ato de ensinar. Percebe-se que o uso de ferramentas digitais está presente não somente em sala de aula, mas nos mais diversos momentos e espaços da vida. Este artigo é resultado de uma pesquisa desenvolvida numa Instituição de Ensino Superior, com objetivo de investigar como docentes de graduação têm ensinado em tempos digitais. Como instrumento de coleta de dados, foi utilizado um questionário semiestruturado, aplicado a docentes do Ensino Superior de uma instituição no interior do Rio Grande do Sul. A pesquisa teve caráter qualitativo, seguindo a perspectiva dos autores Tarouco (2003), Santaella (2014), Braga (2014) e Freire (2002). Resultados obtidos evidenciaram que os docentes buscam cada vez mais utilizar as ferramentas digitais em sala de aula, naturalizando a sua presença, tendo em vista serem instrumentos que fazem parte do cotidiano da vida dos envolvidos no processo.

Palavras-chave: Tecnologias Digitais; Ensino; Aprendizagem.

\begin{abstract}
The presence of digital technologies on contemporary society, brings (leads) us to think about the act of teaching. It is clear that the use of digital tools is present not only inside the classes, but also on the most different spaces an moments in life. This article is the result of a research developed in a Higher Education Institute, and its objective is to investigate how undergraduate teachers have been teaching on digital times. As a data collection, a semi-structured questionnaire was used, applied to higher education teachers from an institution in Rio Grande do Sul. As a qualitative research, following the author's perspectives as Tarouco (2003), Santaella (2014), Braga (2014) and Freire (2002). The results obtained evidenced that the teachers seek for introducing the use of digital technologie tools on their classes, naturalizing its presence, considering that those tools make part of a daily life of those involved in the process.
\end{abstract}

Keywords: Digital Technologies; Teaching; Learning. 


\section{INTRODUÇÃO}

A efetivação do conhecimento, nos últimos anos, tem passado por mudanças. Da tradição oral passou-se à escrita, que proporcionou a formalização do conhecimento. Contemporaneamente, as Tecnologias Digitais de Informação e Comunicação (TDICs) estão levando a um novo tempo, que atinge diretamente o ambiente escolar e acadêmico. $\mathrm{O}$ surgimento da internet, por sua vez, ampliou o acesso e o compartilhamento de informações e conhecimentos em larga escala. Informações que antes eram de difícil acesso, agora podem ser buscadas em instantes, o que auxilia alunos e professores.

Com isso, o modo de se relacionar com o conhecimento, assim como as estratégias de Ensino, tem mudado significativamente. A pesquisa situou-se nessa problemática, buscando compreender como os professores que atuam no ensino superior estão desenvolvendo o seu trabalho, especialmente com relação à presença das TDICs. Como é sabido, o mau uso das TDICs, ou seja, o uso ao avesso, pode ser paralisante, na medida em que a reprodução, na íntegra, de textos e informações, pode levar à ausência do raciocínio lógico e da exposição argumentativa e, assim, a tautologias.

O estudo, então, visou investigar como professores de graduação, mestrado e doutorado estão ensinando em tempos digitais. Para tanto, seguiu-se uma metodologia qualitativa, buscando os dados junto a três docentes que atuam em uma instituição de ensino superior do Rio Grande do Sul, mantendo o foco nas TDICs.

\section{REFERENCIAL TEÓRICO}

A chegada das tecnologias digitais de informação e comunicação trouxe profundas mudanças no ensino e na aprendizagem. A pedagogia tradicional vem perdendo espaço, diante do surgimento de maneiras diferentes de conduzir as aulas. Na lógica tradicional, o professor é o detentor do saber e transmite o conteúdo sem que haja iniciativas e protagonismo dos estudantes. Neste modelo, o aluno somente absorve o conhecimento que já vem pronto, formalizado, e o reproduz, seja em textos ou provas. $\mathrm{O}$ aluno mantém a postura de mero ouvinte. Não interage e não desenvolve sua autonomia dentro e fora de sala de aula.

A esse respeito, Freire (2002, p. 27) corrobora afirmando que "ensinar não é transferir conhecimento, mas criar as possibilidades para a sua própria produção ou a sua construção". É dentro desse contexto que, contemporaneamente, o professor se movimenta, tendo que, inclusive, ressignificar a sua função e seu papel de educador no processo de ensino e de aprendizagem. 
Nesse sentido, percebe-se que o uso de novas tecnologias, enquanto estratégia pedagógica, contemporaneamente vem crescendo e ocupando mais espaço nas práticas de sala de aula. De acordo com Demo (2009, p. 53),

O que as novas tecnologias podem nos trazer são oportunidades ainda mais ampliadas, em meio também a enormes riscos e desacertos. [...] Interessa, porém, explorar novas oportunidades de aprendizagem, bem mais centradas na atividade dos alunos, também mais flexíveis e motivadoras, mais capazes de sustentar processos de autoria e autonomia.

Nesse contexto surgem as TDICs e, de modo especial, a internet, a qual disponibiliza o acesso a jogos, vídeos, imagens, animações, softwares, entre outros recursos. Além disso, a leitura dos textos torna-se muito mais atrativa, com a possibilidade de interação com hiperlinks e imagens que favorecem a aprendizagem. Esses recursos surgem vinculados ao ensino com o intuito de fazer do aprendiz o autor do seu próprio conhecimento. Isso com a visão de que o professor não é o único detentor do saber e não deve somente repassar conteúdo, mas sim instigar o aluno a compartilhar saberes e produzir sua capacidade de aprender.

Freire (1996, p. 21) afirma: “Quando entro em uma sala de aula devo estar sendo um ser aberto a indagações, à curiosidade, às perguntas dos alunos, a suas inibições; um ser crítico e inquiridor, inquieto em face da tarefa que tenho - a de ensinar e não a de transferir conhecimento". Daí a importância de o professor estar atento e exercer a função de mediador e problematizador junto ao educando, quando estiver usando as TDICs. Caso contrário, a internet poderá se tornar uma ferramenta que apenas facilita a reprodução de conteúdos formais e fixos, aproximando-se a operações técnicas de copiar e colar conteúdos de sites. Ao professor cabe o cuidado no encaminhamento de suas estratégias de ensino e de aprendizagem, com vistas a evitar problemas de plágios e apropriações indevidas por parte dos alunos.

Atualmente, podemos identificar o uso integral ou parcial das novas tecnologias nas práticas docentes. Os professores muitas vezes identificam a necessidade da inserção de instrumentos digitais no meio educacional, devido às mudanças que vêm acontecendo nas formas de relações, sejam interpessoais ou intrapessoais. Seguindo nessa linha de raciocínio, Santaella (2003, p. 23) afirma que

Já está se tornando lugar-comum afirmar que as novas tecnologias da informação e comunicação estão mudando não apenas as formas do entretenimento e do lazer, mas potencialmente todas as esferas da sociedade: o trabalho (robótica e tecnologias para escritórios), gerenciamento político, atividades militares e policiais (a guerra eletrônica), consumo (transferência de fundos eletrônicos), comunicação e educação (aprendizagem a distância), enfim, estão mudando toda a cultura em geral. 
Os objetos virtuais de aprendizagem (OVAs) são um caminho a ser escolhido para introduzir práticas que façam uso da tecnologia digital. De acordo com o Comitê de Padrões para a Tecnologia, o Learning Technology Standards Comimitee, vinculado ao Instituto de Engenheiros Eletrônicos e Eletricistas (Institute of Electrical and Eletronic Engineers - IEEE), considera-se um objeto de aprendizagem qualquer entidade, digital ou não digital, que pode ser usada, reutilizada ou referenciada durante a aprendizagem com suporte da tecnologia (Braga, 2014). No entanto, Wiley (2000) restringiu esse conceito, referindo-o apenas aos recursos digitais que possam ser utilizados para apoiar a aprendizagem.

Os OVAs são recursos encontrados em repositórios na internet. Nesse sentido, enquanto recursos que podem ser reutilizados, tornam-se atrativos, podendo apoiar a aprendizagem nos contextos educacionais. É de extrema importância que esses objetos digitais sejam interativos. Conforme Braga (2014), quanto mais o aluno conseguir, de forma ativa, absorver informações, refletir, produzir seu próprio conhecimento, mais interativo esse objeto digital pode ser. É necessário também que o objeto de aprendizagem seja utilizado de forma articulada com o conteúdo que está sendo ensinado. Ele deve servir como um complemento e deve fazer sentido para o aluno. Tarouco et al. (2014, p. 14) afirmam que

[...] cada Objeto de Aprendizagem pode se constituir em um módulo com um conteúdo autoexplicativo, que faz sentido e é autossuficiente, sem a necessidade de complementos. Um átomo não pode ser recombinado com qualquer outro tipo de átomo. Essa regra é válida também para os OAs, que precisam estar dentro do mesmo contexto, abranger conteúdos que se relacionem entre si.

Essa recombinação de elementos dos OVAs se dá mediante a participação efetiva dos professores. Em última instância, são os professores os responsáveis pela articulação dos conteúdos em sala de aula. Percebe-se que os professores cada vez mais necessitam atuar como mediadores da aprendizagem, estabelecendo conexões e possibilitando a aproximação entre o estudante e a tecnologia. Nesse sentido, verifica-se que aí existe uma mediação pedagógica, ou seja, de um lado está o aluno e do outro as TDICs.

De acordo com Masetto (2000), a mediação pedagógica pode ser compreendida como uma atitude ou um comportamento no qual o professor se coloca como um facilitador ou motivador. Ele "se apresenta com a disposição de ser uma ponte entre o aprendiz e sua aprendizagem - não uma ponte estática, mas uma ponte 'rolante', que ativamente colabora para que o aprendiz chegue aos seus objetivos" (MASETTO, 2000, p.144-145).

Contemporaneamente uma quantidade gigantesca de informações está disponível através de aparelhos digitais, como é o caso do smartphone. Neste novo contexto, exige-se uma 
atitude de parceria e de corresponsabilidade entre professor e alunos. Assim, ambos devem buscar trabalhar em conjunto, como uma equipe, para atingir objetivos em comum (MASETTO, 2003). Nesse sentido, professor e aluno aprendem juntos, o que não significa que haja a necessidade de diferentes posturas e papéis a serem desempenhados nesse processo.

Como as tecnologias digitais fazem cada vez mais parte da sala de aula, pois, mesmo em disciplinas presenciais, percebe-se uma crescente presença de smartphones e notebooks on line, o professor necessita constantemente repensar a sua própria didática. Isso porque a organização das atividades e do espaço da sala de aula refletem diretamente na aprendizagem dos estudantes.

Gil (2010) aponta para alguns desafios que o docente enfrenta na contemporaneidade e afirma que, para minimizá-los, o professor deve dispor de conhecimentos técnicos e de visão de futuro. Urge que o docente exerça, cada vez mais, o papel de mediador do processo de ensino e de aprendizagem. Nesse sentido, a formação continuada aos docentes se faz necessária, de modo a priorizar o trabalho em equipe, incorporando as tecnologias digitais a estratégias de ensino e de aprendizagem.

\section{Metodologia}

A pesquisa seguiu uma trajetória qualitativa. Neste tipo de pesquisa os investigadores "privilegiam, essencialmente, a compreensão dos comportamentos a partir da perspectiva dos sujeitos da investigação" (BOGDAN; BIKLEN, 1994, p.16). Teve como sujeitos três docentes de uma Instituição de Ensino Superior (IES) do sul do Brasil, os quais embasam suas práticas pedagógicas a partir das ferramentas tecnológicas digitais.

No que diz respeito aos dados coletados, estes emergiram a partir de uma entrevista contendo questões semiestruturadas, na qual, de acordo com Triviños (1987, p. 146), “[...] o informante, seguindo espontaneamente a linha de seu pensamento, de suas experiências dentro do foco principal colocado pelo investigador, começa a participar do conteúdo da pesquisa”.

Os dados foram gravados, posteriormente transcritos e analisados mediante a técnica de Análise Textual Discursiva - ATD (MORAES; GALIAZZI, 2013). A ATD possibilita que os pesquisadores possam analisar a produção a partir de categorias que emergem da fala advinda dos entrevistados. As categorias que emergiram foram: 1. Ensino e aprendizagem além da sala de aula; 2. Planejamento e organização do uso das ferramentas digitais; e 3. Contribuições das ferramentas digitais para a aprendizagem. 
Os entrevistados assinaram Termo de Consentimento Livre e Esclarecido (TCLE), de modo que obtiveram ciência de todas as garantias de não terem nenhum tipo de prejuízo e da possibilidade de se retirarem da pesquisa, caso assim o quisessem, além de não serem identificados. Destaca-se que, para manter o sigilo dos entrevistados, os docentes participantes na pesquisa foram denominados D1, D2 e D3.

\section{AnÁlise e Discussão de Resultados}

Os três docentes entrevistados afirmaram que consideram importante trabalhar com as ferramentas digitais nas suas aulas e que fazem uso delas na sua prática. Houve pequenas diferenças em suas percepções, considerando o modo como os professores inserem as tecnologias digitais em suas aulas. Evidenciou-se que todos percebem a importância do trabalho que estão realizando. Braga (2014, p. 62) enfatiza a necessidade de uma reflexão sistemática por parte dos professores:

Percebe-se, pelo exposto, o quanto a reflexão do professor é importante. Isso comprova que a tecnologia está a serviço da educação, oferecendo novas formas de pesquisa, linguagem e materiais a serem explorados e utilizados, mas nada substitui a ação intencional, reflexiva e planejada do professor.

Como se pode perceber, o professor ocupa uma primazia no processo de ensino e aprendizagem. A partir do conteúdo dos dados coletados na pesquisa, emergiram três diferentes categorias, conforme já exposto, as quais são discutidas a seguir. Ao final, são traçadas algumas aproximações e reflexões acerca das mesmas.

\subsection{ENSINO E APRENDIZAGEM ALÉM DA SALA DE AULA}

Os três entrevistados revelaram preocupação em ensinar e fazer uso de instrumentos digitais com o intuito de que o aprendizado seja reaproveitado além dos espaços de sala de aula. Isso nos remete também à percepção de que as tecnologias digitais estão tão inseridas no dia a dia dos indivíduos, no contexto social, que há uma naturalização crescente da sua presença no cotidiano. Esse fato permite trabalhar com a tecnologia digital, já pressupondo conhecimentos prévios dos alunos a este respeito.

De acordo com Tarouco et al. (2014, p. 31), "Diante de alunos cada vez mais conectados, é natural que os professores busquem novas formas de criação e apresentação do conteúdo, objetivando uma maior proximidade com a realidade desses estudantes". Nesse processo, tanto o professor quanto o aluno têm oportunidade de construírem juntos o conhecimento. Trabalhar com OVAs possibilita essa construção conjunta, que não se restringe ao conteúdo inscrito em 
determinada disciplina. A esse respeito, D2 afirma: "Acho que é mais pensando até futuramente, que eles podem utilizar isso em outra disciplina, né, ou até na vida pessoal deles, que eles vivam isso".

Outro aspecto compreendido, ainda no que diz respeito a adquirir conhecimentos manuseando ferramentas digitais, é o seu uso inclusive em diferentes momentos da graduação. D3 se posiciona, afirmando:

[...] eu sei que no curso de Pedagogia, os relatórios de estágio, eles vêm em vídeos e em relato, em narrativa escrita, que é digital ou impressa. Então, muitas vezes quando eles iniciam em outras disciplinas anteriores ao estágio a editar vídeos, a cuidar de enquadramento, a cuidar o que se escolhe pro vídeo, ou não, isso se faz, de alguma forma, uma aprendizagem digital.

Diante desse novo contexto de acesso às informações e ao conhecimento, a principal função do professor não se restringe mais a ser uma espécie de difusor ou transmissor dos conhecimentos formais e disponíveis. A ideia de um professor enciclopedista, transmissor do conhecimento, está fadada a desaparecer. Até porque a grande questão que permanece não é o acesso às informações, mas como transformar e organizar essas informações para que se chegue ao conhecimento efetivo.

O professor não desaparece nesse contexto, mas é convidado a assumir uma nova postura, no sentido de incentivar e vivenciar os processos de ensino e de aprendizagem juntamente com seus alunos. O professor precisa ser, muito antes, um animador da inteligência coletiva dos grupos que estão sob seu cuidado. Sua atividade centra-se muito mais no acompanhamento e na mediação das aprendizagens, no incitamento à troca dos saberes, à mediação relacional e simbólica, à pilotagem personalizada dos percursos de aprendizagem, e assim por diante (LÉVY, 2010).

\subsection{PlaneJamento e OrganizaÇão do USO De FerRamentas digitais}

Assim como ocorre nas aulas expositivas, que exigem planejamento e organização prévia da aula, a introdução de tecnologia digital nas aulas deve ser bem planejada, a fim de evitar distração e perda do foco. Portanto, é de suma importância que os docentes se preparem e se organizem previamente para fazer uso desses dispositivos em sala de aula.

Mas como o vídeo pode ser trabalhado em aula? O professor pode, por exemplo, trabalhar com temas diversos, criando grupos de pesquisa cujo objetivo final seja a criação de um vídeo. Além disso, ele pode criar e apresentar vídeos para conteúdos mais complexos, de forma a facilitar a aprendizagem dos alunos. $\mathrm{O}$ vídeo, apesar de todo seu potencial de informação e sua capacidade de obter atenção (um dos eventos de instrução de Gagné), deve ser utilizado, assim como outros recursos, de forma integrada às estratégias pedagógicas, com um objetivo bem definido (TAROUCO, 2014, p. 85). 
O entrevistado D2, que atua com audiovisuais, percebe-se reinventando aos poucos e desconstruindo padrões que tempos atrás eram estipulados e trabalhados de modo formal. Nesse sentido, reconhece o potencial e a abertura a novas posturas que o trabalho com as ferramentas tecnológicas possibilita. Ele sustenta sua ideia, dizendo que: "[..] tem gente que começa um vídeo de cabeça pra baixo, então essas coisas que eu acho legal e que eu estou tentando experimentar um pouco, assim, que é deixar eles mais à vontade, para criar e não engessar como a linguagem audiovisual".

Observou-se também que os alunos, quando solicitados, trazem jogos ou atividades virtuais diferentes daquelas já trabalhadas. Na disciplina ofertada pelo D3, percebeu-se claramente essa questão, conforme relato abaixo:

Esse semestre também, em uma das disciplinas, trabalhamos com jogos, uma espécie de jogos, que são o Kahoot e outro que é o Mentimeter, que é aquela nuvem de palavras que foi novidade pra turma e eles gostaram muito, tanto que uma aluna que estava na disciplina usou o mesmo jogo para apresentar em outra turma e foi novidade para a outra turma também. Então foi muito divertido porque foi uma espécie de um jogo digital, que se usou para a aprendizagem (D3).

Contudo, mesmo que os alunos tragam novidades quanto a formas de apresentar trabalhos, D3 destaca que eles ainda apresentam certa repetição no que diz respeito à criatividade: "Como geralmente eu peço a criatividade ou que eles tentem se reinventar algumas vezes, então eles acabam trazendo esses jogos, ou vídeos, músicas... Mas não sai muito disso". Esse dado contribui com a ideia de uma possível acomodação por parte dos discentes, ou até mesmo atesta uma carência de fontes e informações a respeito de outras ferramentas digitais que possam ser utilizadas na aprendizagem. Em contrapartida, a fala de D2 revela outra perspectiva:

E acontece um pouco também isso, que é o que eu estou pesquisando, que é deixar livre e se surpreender na verdade, né e não mostrar muito, "ah, vocês têm que começar com uma imagem padrão BBC", "não façam movimento de câmera", acho que não, porque não existe mais um padrão de BBC, aquele padrão que a gente está acostumado a olhar na televisão, na novela. Hoje o pessoal que está no Youtube é...nossa... completamente diferente, até a questão de gravar na horizontal, na vertical... (D2)

Conforme se pode perceber, o ensino e a aprendizagem mediante uso dos OVAs possibilita um espaço de criação muito maior do que a perspectiva de trabalho focado em manuais e livros didáticos. O vídeo pode ser utilizado para simulações; para produção; na documentação de aulas, projetos e eventos; na elaboração de entrevistas e documentários; além de outras situações. Eis que se abrem espaços para que aluno e professor possam perceber suas atitudes, analisar seus comportamentos, interações e, assim, prover melhorias no processo de ensino (TAROUCO et al., 2014). São espaços que possibilitam experimentações e que 
aproximam professor e aluno. Assim, ambos vão se encontrando em torno da autoprodutividade que se efetiva à medida que vai se desenrolando o processo de produção.

\title{
4.3. PERCEPÇões SObRe a CONTRIbUiÇão daS FERRAMENTAS Digitais
}

Analisando a fala dos entrevistados, mesmo já tendo conhecimento de que os três docentes pautavam suas aulas pensando na utilização de ferramentas digitais, percebeu-se que o resultado do trabalho obtido a partir da realização de vídeos nas disciplinas é positivo.

Segundo o entrevistado D2, um de seus maiores desafios foi articular os conhecimentos e a prática de criação de um objeto virtual de aprendizagem, no caso um vídeo, em uma turma, que, conforme relatou, era muito grande, com cerca de 80 discentes.

\begin{abstract}
A minha percepção é que no início a gente até se assustou um pouco, porque era uma turma relativamente grande, né, mas diria que foi um desafio, que foi muito positivo [...] a gente...nossa... se surpreendeu bastante com a qualidade, e aí também tiveram questões técnicas, alguns tiveram mais dificuldades na parte da edição, outros até na gravação, acabaram tendo dificuldade no roteiro, como desenvolver essa história... (D2)
\end{abstract}

É importante que os Objetos Virtuais de Aprendizagem, assim como a utilização de ferramentas digitais, façam sentido no processo de ensino e de aprendizagem. A ideia de uso das tecnologias com o intuito de cobrir falhas no plano pedagógico não tem sustentação.

A entrevistada D3 relatou que na disciplina ministrada por ela e por outros dois professores, as produções de vídeos tiveram duração de 1 minuto e todas foram apresentadas em uma amostra final da disciplina. Ela afirmou ter sido muito legal, "porque como são todas professoras em formação, falamos da possibilidade de trabalhar o vídeo na escola, ou como aproveitar esse recurso na ideia de uma alfabetização digital ou audiovisual também na escola, que é muito importante".

Nessa mesma direção, Braga (2014) salienta que quando os Objetos de Aprendizagem (OAs) são utilizados de maneira efetiva, eles podem ser grandes aliados no processo educativo. Porém, para que isso aconteça, é necessário que o professor tenha clareza dos objetivos que almeja alcançar e também pesquise, selecione e defina boas estratégias de utilização dos OAs em sala de aula, com o intuito de alcançar os seus objetivos e enriquecer o processo de ensino e de aprendizagem.

\section{CONSIDERAÇÕES FINAIS}

Os dados coletados demonstram que é crescente a presença do contexto tecnológico junto aos processos de ensino e de aprendizagem, com uma crescente naturalização no uso das 
ferramentas digitais. Urge não perder de vista que é necessário ampliar ainda mais a inclusão de recursos tecnológicos na prática pedagógica. Há um enorme campo de ampliação nesse sentido.

Outra questão percebida diz respeito ao incentivo por parte dos docentes para com o aluno, instigando-o a produzir o seu próprio conteúdo, a ser sujeito do seu conhecimento, não apenas participando das atividades. Nesse sentido, Tarouco et al. (2014) destacam que o ensino e a aprendizagem são um processo. Diante das TDICs exige-se, por parte do professor, uma postura de abertura ao diálogo e capacidade de escuta. A partir daí estabelecem-se as condições para que aluno e professor possam desenvolver processos nos quais a parceria se torna uma realidade efetiva. Não se trata de nivelar professor e aluno, mas muito antes de garantir, a ambos, espaços de autonomia, em que todos consigam participar ativamente como sujeitos no processo de ensino e de aprendizagem.

Com este trabalho, pôde-se perceber que os docentes trabalham em suas práticas pedagógicas com as tecnologias digitais de forma a se tornarem mediadores entre essas ferramentas digitais e os alunos. O trabalho com OVAs leva ao incentivo crescente, pois instiga o aluno a desenvolver a autonomia e a autoria, com destaque especial à sua visão de mundo e a formas de expressar suas ideias em sala de aula e também na vida pessoal.

\section{REFERÊNCIAS}

BOGDAN, Robert; BIKLEN, Sari Knopp. A investigação qualitativa em educação. Portugal: Porto, 1994.

BRAGA, Juliana Cristina. Objetos de Aprendizagem, volume 1: introdução e fundamentos. Santo André: Editora da UFABC, 2014.

DEMO, Pedro. Aprendizagens e Novas Tecnologias. Revista Brasileira de Docência, Ensino e Pesquisa em Educação Física. v. 1, n. 1, p.53-75, 2009.

FREIRE, Paulo. Pedagogia da Autonomia Saberes Necessários à Prática Educativa. São Paulo: Paz e Terra, 2002.

GIL, Antônio Carlos. Didática do Ensino Superior. 1. Ed. São Paulo: Atlas, 2010

LÉVY, Pierre. Cibercultura. São Paulo: Editora 34, 2010.

MASETTO, Marcos Tarciso. Competência Pedagógica do Professor Universitário. São Paulo: Summus, 2003.

MORAES, Roque; GALIAZZI, Maria do Carmo. Análise Textual Discursiva. 2. Ed. Ijuí: Unijuí, 2013. 
SANTAELLA, Lucia. Da cultura das mídias à cibercultura: o advento do pós-humano. Revista FAMECOS. Porto Alegre, n. 22, 2003.

TAROUCO, Liane Margarida Rockenbach; COSTA, Valéria Machado da; ÁVILA, Bárbara Gorziza; BEZ; Marta Rosecler; SANTOS, Edson Felix dos. Objetos de Aprendizagem: Teoria e Prática. Porto Alegre: Evangraf, 2014.

TRIVIÑOS, Augusto Nibaldo Silva. Introdução à pesquisa em ciências sociais: a pesquisa qualitativa. São Paulo: Atlas, 1987.

WILEY, David. Connecting learning objects to instructional design theory: A definition, a metaphor, and a taxonomy. In: WILEY, David (Ed.) The Instructional Use of Learning Objects. 2000. Versão Online. Disponível em: http://reusability.org/read/chapters/wiley.doc . Acessado em: 12 set. 2018.

Recebido em: 14 de agosto de 2019. Aprovado em: 01 de dezembro de 2019. 